\title{
Size matters in Triticeae polyploids: larger genomes have higher remodeling
}

\author{
Miguel Bento, J. Perry Gustafson, Wanda Viegas, and Manuela Silva
}

\begin{abstract}
Polyploidization is one of the major driving forces in plant evolution and is extremely relevant to speciation and diversity creation. Polyploidization leads to a myriad of genetic and epigenetic alterations that ultimately generate plants and species with increased genome plasticity. Polyploids are the result of the fusion of two or more genomes into the same nucleus and can be classified as allopolyploids (different genomes) or autopolyploids (same genome). Triticeae synthetic allopolyploid species are excellent models to study polyploids evolution, particularly the wheat-rye hybrid triticale, which includes various ploidy levels and genome combinations. In this review, we reanalyze data concerning genomic analysis of octoploid and hexaploid triticale and different synthetic wheat hybrids, in comparison with other polyploid species. This analysis reveals high levels of genomic restructuring events in triticale and wheat hybrids, namely major parental band disappearance and the appearance of novel bands. Furthermore, the data shows that restructuring depends on parental genomes, ploidy level, and sequence type (repetitive, low copy, and (or) coding); is markedly different after wide hybridization or genome doubling; and affects preferentially the larger parental genome. The shared role of genetic and epigenetic modifications in parental genome size homogenization, diploidization establishment, and stabilization of polyploid species is discussed.
\end{abstract}

Key words: genome restructuring, Triticeae, synthetic hybrids, polyploids.

Résumé : La polyploïdisation est l'une des forces motrices les plus importantes de l'évolution chez les plantes et joue un rôle important dans la spéciation et la création de diversité. Elle mène à un ensemble d'altérations génétiques et épigénétiques qui génèrent ultimement des plantes et des espèces avec une plasticité génomique accrue. Les polyplö̈des résultent de la fusion de deux génomes ou plus au sein d'un même noyau et sont classifiés en allopolyploïdes (des génomes différents) et autopolyploïdes (le même génome). Les allopolyploïdes synthétiques chez les Triticées constituent d'excellents modèles pour étudier l'évolution des polyploïdes. Cela est particulièrement le cas pour le triticale, un hybride entre le blé et le seigle, lequel présente divers niveaux de plö̈die et combinaisons génomiques. Dans cette synthèse, les auteurs réexaminent les données portant sur l'analyse génomique de triticales hexaploïdes et octoploïdes, ainsi que différents blés hybrides synthétiques, en les comparant à d'autres espèces polyploïdes. Cette analyse révèle d'importants changements dans la structure des génomes chez le triticale et les blés hybrides dont : la disparition de bandes parentales majeures et l'apparition de nouvelles bandes. De plus, les données montrent que ces réarrangements structuraux dépendent des génomes parentaux, du niveau de ploïdie et du type de séquence (répétitive, à faible nombre de copies et codante/non-codante). Ils diffèrent de façon importante selon qu'ils suivent un croisement interspécifique ou un doublement chromosomique et ils touchent de manière préférentielle le génome parental le plus grand. Les auteurs discutent des rôles partagés que jouent les changements génétiques et épigénétiques dans l'homogénéisation de la taille des génomes parentaux ainsi que dans l'établissement et la stabilisation des espèces polyploïdes

Mots-clés : restructuration des génomes, Triticées, hybrides synthétiques, polyploïdes.

[Traduit par la Rédaction]

\section{Introduction}

Polyploidy is a major mode of evolution in plants, which involves two or more genomes being joined into the same nucleus. It has been estimated that $30 \%-70 \%$ of plant species are of polyploid origin, an assessment that is approaching $100 \%$ if paleopolyploids are included (Wendel 2000; Wolfe 2001). Polyploids are classified into autopolyploids

Received 23 June 2010. Accepted 5 November 2010. Published on the NRC Research Press Web site at genome.nrc.ca on 18 February 2011.

Corresponding Editor: T. Schwarzacher.

M. Bento, W. Viegas, and M. Silva. ${ }^{1}$ Centro de Botânica Aplicada à Agricultura, Secção de Genética, Instituto Superior de Agronomia, Technical University of Lisbon, Tapada da Ajuda 1349-017 Lisboa, Portugal.

J.P. Gustafson. USDA-ARS, Plant Genetics Research Unit, University of Missouri, Columbia, MO 65211-7020, USA.

${ }^{1}$ Corresponding author (e-mail: manuelasilva@isa.utl.pt). 


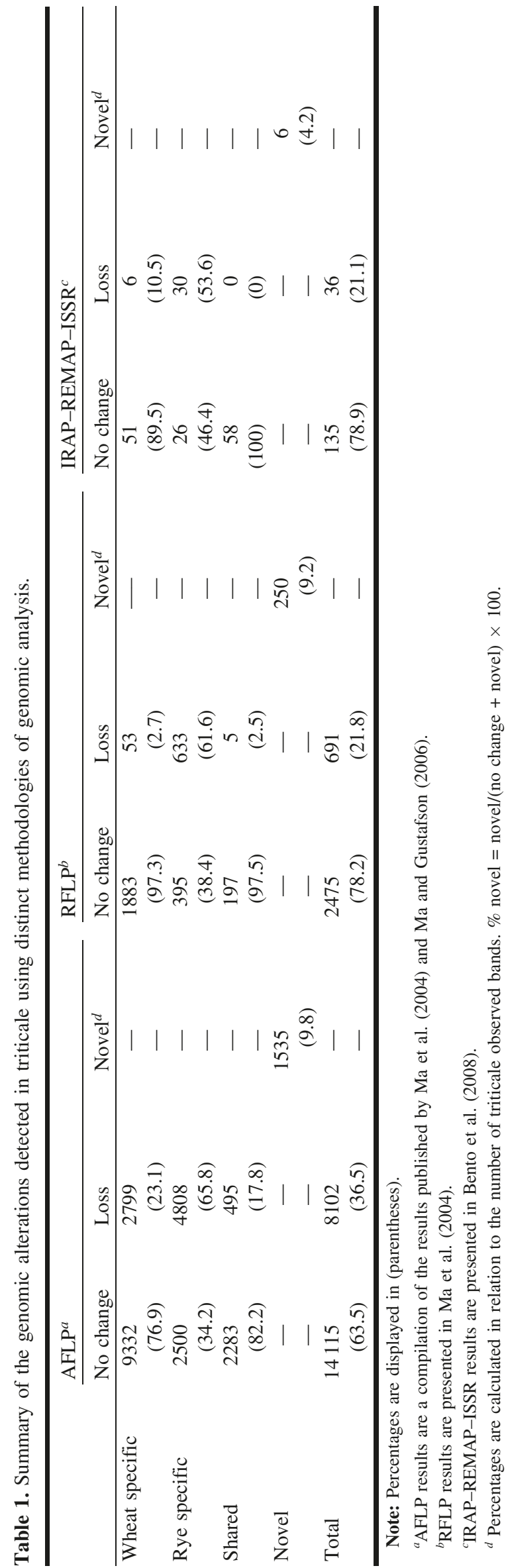

and allopolyploids based on the origin of the component genomes and can be represented by many different ploidy levels. An autopolyploid results from the doubling of a diploid genome, and an allopolyploid is formed by the combination of two or more different, but usually related, genomes through hybridization between distinct species or genera. Gene redundancy in polyploids is obvious and leads to new expression patterns, which can generate developmental novelty and the appearance of new phenotypes, producing species with a higher degree of genome plasticity when compared with their progenitors (Chen 2007). Furthermore, the loss of self-incompatibility, gain of asexual reproduction, and higher levels of heterozygosity can be fixed in allopolyploids (Comai 2005). These modifications can increase fitness, which may explain the widespread occurrence of polyploids in plants.

Newly synthesized polyploids, with precise known progenitors, are excellent materials to study the emergence of early and late evolutionary genetic and epigenetic events. This approach has been widely applied in many species, such as wheat (Triticum spp.), Arabidopsis, Brassica, cotton (Gossypium spp.), and triticale ( $\times$ Triticosecale) (Dong et al. 2005; Liu et al. 2001; Ma et al. 2004; Ma and Gustafson 2006; Madlung et al. 2005; Ozkan et al. 2001; Salmon et al. 2005). In synthesized polyploids, genetic and (or) epigenetic changes were observed, although their rate, type, and degree are markedly different between distinct polyploids (Chen 2007; Ma and Gustafson 2008). Allopolyploid genomes experience two different phases: a revolutionary phase, occurring immediately after hybridization that is responsible for rapid genetic and epigenetic changes; and an evolutionary phase that corresponds to long-term events, such as slow changes in DNA sequences and functional alterations over time (Feldman and Levy 2005; Levy and Feldman 2002).

Triticale, the first synthesized amphidiploid cereal, is a chromosome-doubled intergeneric hybrid that can be obtained by the cross of distinct wheat species (Triticum spp., AA, $\mathrm{AABB}$, and $\mathrm{AABBDD}$ ) and rye (Secale cereale $\mathrm{L}$., $\mathrm{RR}$ ), producing various genome combinations and ploidy levels, such as tetraploid AARR, hexaploid AABBRR, and octoploid AABBDDRR. When compared with other allopolyploids, triticale is a very complex genome because of its high ploidy level, large genome size, and the distant relationships between parental genomes. However, because of its short history and accumulated pedigree knowledge, it becomes a very useful model species to study evolutive processes mediated by polyploidization. Synthetic allotetrapolyploids involving Aegilops spp. and Triticum spp. have also been analyzed in comparison with their parental species in an attempt to simulate natural wheat allopolyploids. The aims of this review are to summarize findings obtained so far in Triticeae polyploid species and compare results with other allopolypoid species.

\section{Polyploid genomic analysis}

Overall, genomic sequence changes have been extensively studied in Triticeae polyploids involving different octoploid and hexaploid triticales, the corresponding $\mathrm{F}_{1}$ hybrids, and their respective parental genomes to assess polyploidizationinduced genome readjustments using molecular marker tech- 
Table 2. Re-evaluation of collected data of percent parental band loss/elimination by sequence type in octoploid and hexaploid triticales.

\begin{tabular}{|c|c|c|c|c|c|c|}
\hline \multirow[b]{2}{*}{ Analysis } & \multirow[b]{2}{*}{ Sequence type } & \multirow[b]{2}{*}{ Parental genome } & \multicolumn{4}{|c|}{$\%$ elimination } \\
\hline & & & $\mathrm{CS} \times \mathrm{I}$ & $\mathrm{H} \times \mathrm{K}$ & $\mathrm{C} \times \mathrm{S}$ & $\mathrm{C} \times \mathrm{U}$ \\
\hline \multirow{3}{*}{$\mathrm{AFLP}^{a}$} & & $\mathrm{R}$ & 61.1 & 65.5 & 62.5 & 67.8 \\
\hline & Low copy & $\mathrm{W}$ & 8.7 & 6.6 & 14.8 & 15.6 \\
\hline & & $\mathrm{R}$ & 69.8 & 69.7 & 61.1 & 68.8 \\
\hline \multirow[t]{2}{*}{ IRAP-REMAP-ISSR ${ }^{c}$} & Repetitive motifs-flanking regions & $\mathrm{W}$ & 10.5 & - & - & - \\
\hline & & $\mathrm{R}$ & 53.6 & - & - & - \\
\hline
\end{tabular}

Note: W, wheat; R, rye $(2 n=2 x)$; CS, 'Chinese Spring' $(2 n=6 x)$; I, 'Imperial'; H, 'Holdfast' $(2 n=6 x)$; K, 'King II'; C, 'Cocorit 71' (2n= 4x); S, 'Snoopy'; U, 'UC90'. Percentages were calculated separately for each parent and shared bands are not taken into consideration (results for eliminated shared bands are not shown). \% elimination $=($ specific type of parental bands eliminated $) /($ total of specific type of parental bands detected $) \times 100$.

${ }^{a}$ AFLP results are a compilation of the results published by Ma et al. (2004) and Ma and Gustafson (2006).

${ }^{b}$ RFLP results are presented in Ma et al. (2004).

'IRAP-REMAP-ISSR results are presented in Bento et al. (2008).

Table 3. Collected data from Dong et al. (2005) and Shaked et al. (2001) on percent parental band loss/ elimination using AFLP (repectitive sequence type) in Aegilops $\times$ Aegilops, Aegilops $\times$ Triticum, and Triticum $\times$ Aegilops polyploid genotypes.

\begin{tabular}{lll}
\hline $\begin{array}{l}\text { Polyploid } \\
\text { genotype }\end{array}$ & $\begin{array}{l}\text { Parental } \\
\text { genome }\end{array}$ & $\begin{array}{l}\text { \% elimination } \\
\text { of total bands }\end{array}$ \\
\hline As $\times \mathrm{Au}$ & $\mathrm{As}$ & 14 \\
& $\mathrm{Au}$ & 0.5 \\
$\mathrm{Al} \times \mathrm{Tu}$ & $\mathrm{Al}$ & 12.2 \\
& $\mathrm{Tu}$ & 11.4 \\
$\mathrm{Tt} \times \mathrm{At}$ & $\mathrm{Tt}$ & 21 \\
& $\mathrm{At}$ & 12.3 \\
\hline
\end{tabular}

Note: As, Ae. sharonensis $(2 n=2 x)$; Au, Ae. umbellulata $(2 n=2 x) ; \mathrm{Al}$, Ae. longissima $(2 n=2 x) ; \mathrm{Tu}, T$. urartu $(2 n=$ $2 x)$; Tt, T. turgidum $(2 n=4 x)$; At, Ae. tauschii $(2 n=2 x)$.

niques, such as amplified fragment length polymorphism (AFLP) and restriction fragment length polymorphism (RFLP) analysis (Ma et al. 2004; Ma and Gustafson 2006). AFLP analysis was used to study different synthetic wheat allotetraploids between Aegilops spp. and Triticum spp., $\mathrm{F}_{1}$ hybrids, and their homozygous diploid parents (Dong et al. 2005; Shaked et al. 2001). Large-scale AFLP studies were implemented to obtain an unbiased genome-wide estimation of the occurrence of genomic sequence variation using different restriction enzymes, namely EcoRI-MseI primers, which amplify repetitive sequences (Dong et al. 2005; Ma et al. 2004; Ma and Gustafson 2006; Shaked et al. 2001) and Pst I-MseI primers, which predominantly target lowcopy sequences most present in distal gene-rich regions, as Pst I is highly sensitive to the cytosine status (Milla and Gustafson 2001; Young et al. 1999). Furthermore, coding sequence variation induced by polyploidization in Triticeae was investigated using cDNA-probed RFLP analyses (Ma et al. 2004).

Utilizing a wide series of primer combinations, octoploid triticale amphidiploids and their wheat and rye parental genomes were analyzed using inter-retrotransposon amplified polymorphism (IRAP), retrotransposon-microsatellite ampli- fied polymorphism (REMAP), and inter-simple sequence repeat (ISSR) techniques (Bento et al. 2008). IRAP, REMAP, and ISSR are PCR-based molecular marker techniques initially designed to identify different barley (Hordeum vulgare L.) cultivars (Kalendar et al. 1999) combining primers designed for long terminal repeat (LTR) retrotransposons, which have a very important role in genome evolution and speciation owing to their dynamics and potential mobility (Vitte and Panaud 2005), and (or) microsatellites, which constitute polymorphic loci present throughout nuclear DNA, preferentially associated with retrotransposons in cereals (Ramsay et al. 1999). Primers designed to evaluate LTRs point outwards and amplify retrotransposon-flanking sequences, thus allowing for the detection of retrotransposon insertional polymorphisms (Kalendar and Schulman 2006).

Recently, a more specific molecular marker system involving single sequence repeat (SSR), originally designed to study unique sequences containing microsatellites in the wheat genome (Röder et al. 1998), was used to study variation induced by polyploidization in triticale with different combinations of wheat and rye parents (Tang et al. 2008).

The above molecular marker systems were crucial to disclosing genomic modifications induced by polyploidization, allowing the detection of extensive changes accessed by alterations in banding profiles. AFLP and RFLP analyses allowed for a genome-wide range evaluation offering the possibility to differentiate between genome euchromatic and heterochromatic fractions. Whereas, IRAP, REMAP, and ISSR, which are unaffected by DNA methylation (Kalendar and Schulman 2006) and specific for repetitive motifs such as retrotransposons (Vitte and Panaud 2005), allowed for the detection of rearrangements involving both repetitive and coding sequences (Bento et al. 2008).

\section{Genome rearrangement events revealed by band losses}

The results obtained by the analysis of triticale polyploids were re-evaluated and have been summarized in Table 1, and clearly disclosed the high level of genome restructuring events associated with polyploid establishment (Bento et al. 


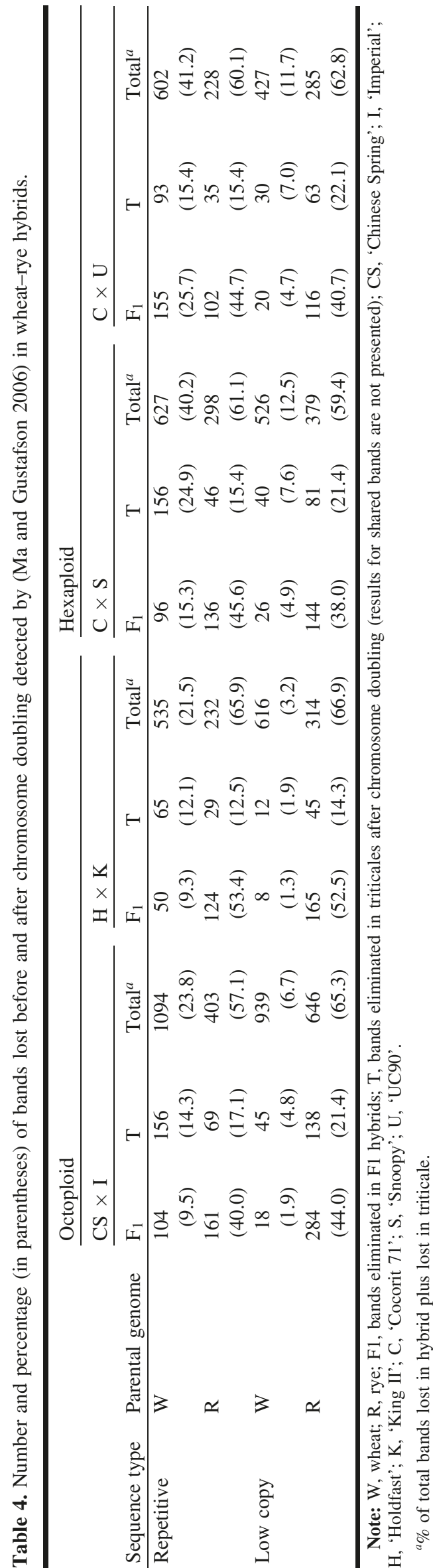

2008; Kashkush et al. 2002; Ma et al. 2004; Ma and Gustafson 2006; Tang et al. 2008). Although there are several studies regarding the evaluation of genomic restructuring events in Triticeae hybrids, besides the studies of Dong et al. (2005) and Shaked et al. (2001) (reviewed in Table 2), none discriminate for levels of parental-specific alterations (Feldman et al. 1997; Kashkush et al. 2002; Ozkan et al. 2001; Ozkan et al. 2003; Tang et al. 2008). The data analysis is based on the comparison between parental lines and polyploid gel profiles. Thus, all the bands present in parental gel profiles are considered parental bands and shared bands are the ones present in both parental lines. Conserved bands are bands present in parental profiles and maintained in the polyploid profile, whereas absent bands are bands present in the parental profiles that are missing in the polyploid, indicating the occurrence of a rearrangement event in the polyploid. On the other hand, novel bands are the ones that are present in the newly formed polyploid and absent in parental gel profiles, indicating the occurrence of genome rearrangements. The overall examination of the published results reveal that the variation detected in triticale is significantly higher than that observed in other synthetic polyploids, namely wheat species complexes and Brassica (Song et al. 1995). Such marked differences in polyploid behavior could be due to triticale being of intergeneric origin that may have lead to additional enhanced modifications to parental genomes, thus stabilizing the newly formed polyploid. This hypothesis is reinforced by studies in natural and newly synthesized wheat interspecific polyploids, which suggest lower levels of parental genome restructuring in comparison with triticale (Dong et al. 2005; Feldman et al. 1997; Liu et al. 1998; Ozkan et al. 2001). Similarly, genetic distance is very important when analyzing hybrids within the same genus; for example, crosses between Brassica rapa and Brassica nigra revealed a higher genome variation than the crosses between the more closely related species $B$. rapa and Brassica oleracea (Song et al. 1995). The same was observed in hybrids among members of the Triticeae where an interspecific cross between Aegilops sharonensis and Aegilops umbellulata revealed lower variation (6.7\%) than an intergeneric cross between Aegilops longissima and Triticum urartu (11.8\%) (Shaked et al. 2001) or Triticum turgidum and Aegilops tauschii (17.2\%) (Dong et al. 2005).

The rearrangements detected in triticale by AFLP-RFLP and IRAP-REMAP-ISSR analysis (Bento et al. 2008; Ma et al. 2004; Ma and Gustafson 2006; Tang et al. 2008) established the disappearance of bands from both parental origins and the emergence of novel bands absent in the progenitor's banding profiles. The appearance of novel bands was also described in Brassica polyploids (Song et al. 1995). Not surprisingly, the triticale genome analyses clearly demonstrated that the disappearance of parental bands was much more frequent than the appearance of novel bands. The percentage of band disappearance (Table 1) varied between $36.5 \%$ (detected by AFLP) and $21.1 \%$ (detected by IRAP-REMAP-ISSR), whereas the appearance of novel bands was $9.8 \%$ (detected by AFLP), 9.2\% (detected by RFLP), and $4.2 \%$ (detected by IRAP-REMAP-ISSR) (Bento et al. 2008; Ma et al. 2004; Ma and Gustafson 2006). Similar results were reported in other polyploids involving Triticum, Brassica, and Spartina (Dong et al. 2005; Kashkush et 
Table 5. Number and percentage (in parentheses) of bands lost before and after chromosome doubling detected by (Shaked et al. 2001) in Aegilops $\times$ Aegilops and Aegilops $\times$ Triticum hybrid genotypes.

\begin{tabular}{|c|c|c|c|c|c|c|c|c|}
\hline \multirow[b]{2}{*}{ Sequence type } & \multirow[b]{2}{*}{ Parental genome } & \multicolumn{3}{|c|}{$\mathrm{As} \times \mathrm{Au}$} & \multicolumn{3}{|c|}{$\mathrm{Al} \times \mathrm{Tu}$} & \multirow[b]{2}{*}{ Global } \\
\hline & & $\mathrm{F}_{1}$ & A & Total $^{a}$ & $\mathrm{~F}_{1}$ & A & Total $^{a}$ & \\
\hline \multirow[t]{8}{*}{ Repetitive $^{b}$} & As & 20 & 4 & 171 & - & - & - & \multirow{4}{*}{$\begin{array}{l}25 \\
(6.7)\end{array}$} \\
\hline & & (11.7) & $(2.3)$ & (14) & - & - & - & \\
\hline & \multirow[t]{2}{*}{$\mathrm{Au}$} & 0 & 1 & 202 & - & - & - & \\
\hline & & (0) & $(0.5)$ & $(0.5)$ & - & - & - & \\
\hline & \multirow[t]{2}{*}{$\mathrm{Al}$} & - & - & - & 12 & 10 & 180 & \multirow{4}{*}{$\begin{array}{l}41 \\
(11.8)\end{array}$} \\
\hline & & - & - & - & $(15.0)$ & $(27.5)$ & $(12.2)$ & \\
\hline & \multirow[t]{2}{*}{$\mathrm{Tu}$} & - & - & - & 1 & 18 & 166 & \\
\hline & & - & - & - & $(0.6)$ & $(10.8)$ & (11.4) & \\
\hline
\end{tabular}

Note: As, Ae. sharonensis; Au, Ae. umbellulata; Al, Ae. longissima; Tu, T. urartu; $\mathrm{F}_{1}$, bands eliminated in F1 hybrids; A, bands eliminated in allotetraploids after chromosome doubling.

${ }^{a} \%$ of total bands lost in hybrid plus lost in allotetraploid.

${ }^{b}$ Results are only for non-methylation-sensitivite enzymes.

al. 2002; Salmon et al. 2005; Shaked et al. 2001; Song et al. 1995). Sequence restructuring, therefore, seems to be a widespread phenomenon associated with newly formed polyploids (Leitch and Bennett 2004). The exception to genome downsizing was reported in cotton (Gossypium) polyploids (Liu et al. 2001) where genomic changes were not detected by AFLP, although a reduction in C-DNA values was observed when these polyploids where compared with parental genomes (Bennett 1977; Bin and Kadir 1976).

\section{Genome rearrangement frequencies in triticale depend on sequence types and wheat ploidy levels}

Sequence rearrangements are not restricted to repetitive and noncoding sequences, as coding sequences, regulatory elements, and promoter regions appear to also be affected by polyploidization (Bento et al. 2008; Ma et al. 2004; Tang et al. 2008), although in different levels. In triticale, repetitive sequences were found to be more frequently rearranged than low-copy and coding sequences (Ma et al. 2004). Published data indicated that $42 \%, 31 \%$, and $22 \%$ of bands were lost from repetitive, low-copy, and coding sequences, respectively (values presented in Ma and Gustafson 2008). Wheat-specific sequence rearrangements are also highly affected by the kind of sequence being analyzed. In octoploid and hexaploid triticale, the level of wheat-specific band loss varied, being approximately $25 \%$ and $46 \%, 7 \%$ and $15 \%$, and $1.5 \%$ and $4 \%$ for repetitive, low-copy, and coding sequences, respectively (Table 2 ). In contrast with the marked differences of wheat-specific band losses, ryespecific bands appear to be lost at similar percentages independent of the type of sequence, ranging between $57.9 \%$ and $69.8 \%$ (Table 2).

The data published by Ma et al. (2004) and Ma and Gustafson (2006) showed that the level of band loss in triticale was distinct for each parental genome (Table 2). Triticale genotype analyses demonstrate that the level of rye parental genome band elimination is higher than the observed level for wheat genome. The maximum percent of wheat-specific band elimination was $47.4 \%$ (detected by AFLP in hexaploid triticale), whereas rye-specific band elimination ranged between $53.6 \%$ (detected in octoploid triticale by IRAP-
REMAP-ISSR analyses) and 69.8\% (detected in octoploid triticale by AFLP analysis). Differences between percentages of rye and wheat-specific band elimination in hexaploid triticales were $18.5 \%$ by AFLP analysis and $62.6 \%$ in octoploid triticale by RFLP analysis.

Gill (1991) suggested that the rye paternal genome being exposed to the adverse environment of maternal wheat cytoplasm in newly formed hybrids could explain its preferential restructuring in triticale. Ma and Gustafson (2008) also suggested that the instability of rye-wheat hybrids may be due to nuclear-cytoplasmatic interactions. However, the Triticeae studies of Dong et al. (2005) and Shaked et al. (2001) contradict the paternal preferential elimination hypothesis, as maternal genome elimination was observed in synthetic wheat (Table 3). When Aegilops speltoides was crossed as female and as male in a study designed to ascertain the effects of cytoplasm on the pattern and rate of sequence elimination, no cytoplasm effects were detected (Ozkan et al. 2001).

On the other hand, as triticale results from an intergeneric hybridization between a polyploid (wheat) and a diploid species (rye), we can consider that wheat has already been subject to genetic and (or) epigenetic modifications during its evolution, thus being more adapted to the polyploidy condition than rye genome. A detailed analysis of data presented in Table 2 reveals a plausible correlation between genome rearrangement percentages and wheat ploidy levels. However, such correlations were absent in the cross between T. turgidum and Ae. tauschii (using enzymes not sensible to methylation), as more genome modifications were detected in the maternal tetraploid genome than in the paternal diploid genome (Table 3).

A higher global genome variation was observed in hexaploid $(40 \%)$ than in octoploid triticale $(\sim 30 \%)$ (Ma and Gustafson 2008), reinforcing previous data (Boyko et al. 1984) showing that DNA content reduction was also higher in hexaploid than in octoploid triticale (28\%-30\% and 9\%, respectively). Although the elimination level of rye-specific bands appears similar both in hexaploid and octoploid triticale, the elimination rate of wheat-specific bands is much higher in hexaploid triticale (for details see Table 2). The mean elimination rate of wheat-specific repetitive sequences in hexaploid triticale was $45 \%$ and $25 \%$ in octoploid triticale, 
Table 7. DNA $1 \mathrm{C}$-value and cell cycle time (CCT) in triticale and wheat and rye parental species.

\begin{tabular}{lcl}
\hline Species & $1 \mathrm{C}-\mathrm{value}{ }^{a}(\mathrm{pg})$ & $\mathrm{CCT}^{b}(\mathrm{~h})$ \\
\hline Secale cereale 'UC90' & 8.3 & 12.0 \\
Triticum turgidum 'Cocorit' & 12.28 & 12.0 \\
$\times$ Triticosecale 'Cocorit' $\times$ 'UC90' & 16.8 & 12.0 \\
\hline
\end{tabular}

${ }^{a}$ Plant DNA C-values database, Royal Botanic Gardens, Kew, UK. ${ }^{b}$ Kidd et al. 1987.

revealing a higher buffering capacity of hexaploid wheat genome to avoid large numbers of sequence rearrangements in triticale. Such correlations between parental ploidy level and genome alteration rate have not been established in other species such as cotton and wheat (Aegilops $\times$ Triticum) polyploids (Liu et al. 1998; Ozkan et al. 2001).

The results indicate that each triticale parental genome is subjected to distinct regulatory systems. In the wheat-origin genome, each type of sequence seems to have different relevancies in genome adaptation through polyploidization, and the elimination of different sequences is apparently controlled accordingly. Contrastingly, the rye-origin genome appears to be highly restructured upon polyploidization independently of sequence type considered.

\section{Parental genomes are differently restructured during hybridization and polyploidization}

The data obtained for two hexaploid and two octoploid triticales, their respective parental lines, and their correspondent $\mathrm{F}_{1}$ hybrids (Ma and Gustafson 2006) clearly demonstrated the occurrence of two major stages of restructuring events. First during the formation of the wide hybrid, followed by a second after chromosome doubling of the hybrid. The reanalyzed results are summarized in Table 4, revealing during the first stage an immediate and drastic response to hybridization, whereas in the second stage a continuous process of changes occurring at a slower rate (Ma and Gustafson 2006). Similar results, presented in Table 5, were described by Shaked et al. (2001) in Aegilops $\times$ Aegilops and Aegilops $\times$ Triticum crosses and also reported in Aegilops $\times$ Triticum and Spartina $\mathrm{F}_{1}$ hybrids, although not so pronounced (Ozkan et al. 2001; Salmon et al. 2005).

The enhanced modification levels observed when rye genome interacts either with hexaploid or tetraploid wheat genomes appears to be mainly the result of adjustments occurring immediately after hybridization. Curiously, the rate of band elimination observed after $\mathrm{F}_{1}$ hybrid chromosome doubling is very similar for wheat and rye repetitive sequences, ranging between $12 \%$ and $17 \%$, for most triticales except one hybrid analyzed by Ma and Gustafson (2006) in which the level of wheat repetitive bands lost was almost 25\%. Moreover, Ma and Gustafson (2006) noted in two sets of wheat-rye hybrids that hexaploid wheat repetitive sequences had a higher buffer capacity and less changes in comparison with tetraploid wheat genome $(24.8 \%$ and $25.2 \%$ versus $44 \%$ and $47.4 \%$, respectively).

In all wheat-rye $F_{1}$ hybrids and correspondent triticale studied (Ma and Gustafson 2006), a preferential elimination of bands associated to repetitive rather than low-copy se- 
quences was observed concerning the wheat parental genome. Conversely, rye-origin repetitive and low-copy sequences were altered in similar level in the hybrid and after chromosome doubling. Therefore, it is clear that bands associated with coding sequences are comparatively more eliminated in rye than in wheat. Such preferential genome elimination can drastically reduce homeologues gene copies avoiding gene redundancy, favoring a "diploid" behavior and further polyploid stabilization, as proposed (Feldman et al. 1997).

\section{Size matters in triticale genome rearrangements: larger genomes are more affected}

As described earlier, major genomic restructuring events were identified in triticale at higher percentages than in any other polyploid studied, which affected variation in repetitive, low-copy, and coding sequences present in the genome. Analysis of triticale confirmed early suggestions on the mechanisms involved in polyploidization adjustment, but also revealed new concerns. The idea that sequence elimination is a major event involved in the stabilization of newly formed polyploids was reinforced by the results reviewed, as the overall number of sequences lost confirmed previous descriptions on genome size decrease in triticale (Boyko et al. 1984). In the studies of Ozkan et al. (2003) and Eilam et al. (2008) an extensive list of genome downsizing examples in Aegilops $\times$ Triticum hybrid genotypes was presented. Moreover, it was recently shown that the absence of ryeorigin bands in wheat-rye hybrid genotypes resulted from sequence elimination rather than from changes to primer annealing sites (Bento et al. 2010).

The higher degree of paternal genome elimination observed in triticale is not the general rule that has been observed in other newly formed polyploids. In Table 6, preferential parental genome elimination is presented for some Triticeae polyploids, showing that the maternal genome can also show preferential sequence elimination, contradicting the hypothesis of Gill (1991). The results compiled clearly demonstrated that the genome suffering more modifications during polyploidization was always the larger one (comparing DNA contents per haploid genome), independently of their maternal or the paternal status. Thus, the results collected in this review clearly point out, for the first time, the tendency in cereal-wide hybridization for parental genome size homogenization, which preferentially affects the larger genome to stabilize the newly formed polyploid species. Large scale rearrangement events are also observed resulting from the loss of telomeric heterochromatin, a mechanism used to obtain a more balanced nucleotype in triticale (Jouve et al. 1989). Bernardo et al. (1988) demonstrated a clear negative effect of rye heterochromatin on triticale meiotic pairing and that the loss of telomeric heterochromatic blocks are related to yield increase in hexaploid triticale (Gustafson and Bennett 1982). This phenomenon can be the outcome of the relation between nuclear DNA content and the speed of DNA replication (Francis et al. 2008). In fact, the larger parental genome in a hybrid nucleus may not be able to complete the cell cycle by the time of telophase and (or) cell wall formation, thus inducing
DNA elimination through breakage-fusion bridges as previously observed in the early endosperm development of wheat-rye hybrids (Bennett and Gustafson 1982; Gustafson and Bennett 1982). Moreover, those sequence elimination events will certainly preferentially affect late replication repetitive fractions of the genome, namely the dense rye heterochromatic subtelomeric domains (Bennett 1977; Neves et al. 1997).

That hypothesis is reinforced by the effect of DNA C-values in cell cycle duration on correlations between DNA amount, nuclear volume, and cell cycle length in angiosperms (Van't Hof and Sparrow 1963) and in triticale (Kaltsikes 1971; Bennett and Kaltsikes 1973). Recently, the analysis of cell cycle duration in 110 monocots and eudicots species were plotted against the respective nuclear DNA C-values (Francis et al. 2008), and a highly significant regression was observed for all species analyzed, independently of their ploidy level. However, Kidd et al. (1987) presented values for hexaploid triticale in comparison with parental species (Table 7) and surprisingly demonstrated that, although polyploidization leads to an increase on genome size, cell cycle time (CCT) values are constant for progenitors and the polyploid species. They also showed the maintenance of stable cell cycle lengths in hexaploid wheat where the parental CCT values are $11.4 \mathrm{~h}$ in $A$ e. tauschii, and ranged from $11.0 \mathrm{~h}$ to $13.9 \mathrm{~h}$ in $T$. turgidum, but doesn't exceed $14.0 \mathrm{~h}$ in the allopolyploid $T$. aestivum. The clear correlation between nuclear DNA amounts and cell cycle length appears to be associated with genome heterochromatic fraction dimension (reviewed in Redi et al. 2001) and with the speed of DNA replication (Francis et al. 2008). This is where genome restructuring meets epigenetic remodeling of parental genomes allocated to the same nuclear background. In fact, more than just genome rearrangements are necessary for the adjustment of both parental genomes following polyploidization, chromatin remodeling also mediates required changes when two species share a common hybrid nucleus. Viegas et al. (2002) proposed a model explaining chromatin-imprinting control of nucleolar dominance in polyploid species, based on the importance of genome size in such interactions. With the Viegas et al. (2002) model, differences in genome size owing to repetitive DNA sequence variation allocated in heterochromatin domains should induce the need for greater elimination events in the larger rye genome, to properly "accommodate" in the hybrid nucleus. Following such hypothesis, more intimate associations between heterochromatic domains should also occur, modifying expression patterns of neighboring genes. Epigenetic functional fine tuning of parental genomes together with preferential rearrangements of the larger parental genome will, therefore, certainly assist polyploid genome downsizing. Genetic and epigenetic modifications seem, therefore, crucial to establish the diploid-like behavior and speciation of polyploid genomes, as proposed by $\mathrm{Ma}$ and Gustafson (2005).

\section{Acknowledgements}

Miguel Bento is funded by a doctoral scholarship (SFRH/ BD/28657/2006) by Fundação para a Ciência e a Tecnologia, Portugal. This research was financed by Fundação para 
a Ciência e a Tecnologia (Project PTDC/BIA-BEC/101964/ 2008).

\section{References}

Bennett, M.D. 1977. Heterochromatin, aberrant endosperm nuclei and grain shrivelling in wheat-rye genotypes. Heredity, 39(3): 411-419. doi:10.1038/hdy.1977.83.

Bennett, M.D., and Gustafson, J.P. 1982. The effect of telomeric heterochromatin from Secale cereale on triticale $(\times$ Triticosecale). II. The presence or absence of blocks of heterochromatin in isogenic backgrounds. Can. J. Genet. Cytol. 24(1): 93-100. doi:10.1139/g82-009 .

Bennett, M.D., and Kaltsikes, P.J. 1973. The duration of meiosis in a diploid rye, tetraploid wheat and the hexaploid triticale direved from them. Can. J. Genet. Cytol. 15(4): 671-679. doi:10.1139/ g73-080 .

Bento, M., Pereira, H.S., Rocheta, M., Gustafson, P., Viegas, W., Silva, M., and Fraser, J. 2008. Polyploidization as a retraction force in plant genome evolution: sequence rearrangements in triticale. PLoS One, 3(1): e1402. doi:10.1371/journal.pone. 0001402. PMID: 18167561.

Bento, M., Gustafson, P., Viegas, W., and Silva, M. 2010. Genome merger: from sequence rearrangements in triticale to their elimination in wheat-rye addition lines. Theor. Appl. Genet. 121(3): 489-497. doi:10.1007/s00122-010-1325-6. PMID:20383487.

Bernardo, A., Garcia, M., and Jouve, N. 1988. The effect of Secale cereale $\mathrm{L}$. heterochromatin on wheat chromosome-pairing. Genetica, 77(2): 89-95. doi:10.1007/BF00057758.

Bin, Z., and Kadir, A. 1976. DNA evolution in the genus Gossypium. Chromosoma, 56(1): 85-94. doi:10.1007/BF00293732.

Boyko, E.V., Badaev, N.S., Maximov, N.G., and Zelenin, A.V. 1984. Does DNA content change in the course of triticale breeding? Cereal Res. Commun. 12(1-2): 99-100.

Chen, Z.J. 2007. Genetic and epigenetic mechanisms for gene expression and phenotypic variation in plant polyploids. Annu. Rev. Plant Biol. 58(1): 377-406. doi:10.1146/annurev.arplant. 58.032806.103835. PMID:17280525.

Comai, L. 2005. The advantages and disadvantages of being polyploid. Nat. Rev. Genet. 6(11): 836-846. doi:10.1038/nrg1711. PMID:16304599.

Dong, Y.Z., Liu, Z.L., Shan, X.H., Qiu, T., He, M.Y., and Liu, B. 2005. Allopolyploidy in wheat induces rapid and heritable alterations in DNA methylation patterns of cellular genes and mobile elements. Russ. J. Genet. 41(8): 890-896. doi:10.1007/ s11177-005-0177-7.

Eilam, T., Anikster, Y., Millet, E., Manisterski, J., and Feldman, M. 2008. Nuclear DNA amount and genome downsizing in natural and synthetic allopolyploids of the genera Aegilops and Triticum. Genome, 51(8): 616-627. doi:10.1139/G08-043. PMID: 18650951.

Feldman, M., and Levy, A.A. 2005. Allopolyploidy — a shaping force in the evolution of wheat genomes. Cytogenet. Genome Res. 109(1-3): 250-258. doi:10.1159/000082407. PMID: 15753584.

Feldman, M., Liu, B., Segal, G., Abbo, S., Levy, A.A., and Vega, J.M. 1997. Rapid elimination of low-copy DNA sequences in polyploid wheat: a possible mechanism for differentiation of homoeologous chromosomes. Genetics, 147(3): 1381-1387. PMID:9383078.

Francis, D., Davies, M.S., and Barlow, P.W. 2008. A strong nucleotypic effect on the cell cycle regardless of ploidy level. Ann. Bot. (Lond.), 101(6): 747-757. doi:10.1093/aob/mcn038.

Gill, B.S. 1991. Nucleocytoplasmic interaction (NCI) hypothesis of genome evolution and speciation in polyploid plants evolution and speciation in polyploid plants. In Proceedings of the Kihara Memorial International Symposium on Cytoplasmic Engineering in Wheat. Edited by T. Sasakurma. Yokohama, Japan. pp. 4853.

Gustafson, J.P., and Bennett, M.D. 1982. The effect of telomeric heterochromatin from Secale cereale on triticale $(\times$ Triticosecale). I. The influence of the loss of several blocks of telomeric heterochromatin on early endosperm development and kernel characteristics at maturity. Can. J. Genet. Cytol. 24(1): 83-92.

Jouve, N., Galindo, C., Mesta, M., Diaz, F., Albella, B., Garcia, P., and Soler, C. 1989. Changes in triticale chromosome heterochromatin visualized by C-banding. Genome, 32(5): 735-742.

Kalendar, R., and Schulman, A.H. 2006. IRAP and REMAP for retrotransposon-based genotyping and fingerprinting. Nat. Protoc. 1(5): 2478-2484. doi:10.1038/nprot.2006.377. PMID: 17406494.

Kalendar, R., Grob, T., Regina, M., Suoniemi, A., and Schulman, A. 1999. IRAP and REMAP: two new retrotransposon-based DNA fingerprinting techniques. Theor. Appl. Genet. 98(5): 704-711. doi:10.1007/s001220051124.

Kaltsikes, P.J. 1971. The mitotic cycle in an amphiploid (triticale) and its parental species. Can. J. Genet. Cytol. 13(4): 656-662. doi:110.1139/g71-094.

Kashkush, K., Feldman, M., and Levy, A.A. 2002. Gene loss, silencing and activation in a newly synthesized wheat allotetraploid. Genetics, 160(4): 1651-1659. PMID:11973318.

Kidd, A.D., Francis, D., and Bennett, M.D. 1987. Replicon size, mean rate of DNA replication and the duration of the cell cycle and its component phases in eight monocotyledonous species of contrasting $C$ values. Ann. Bot. 59(6): 603-609.

Leitch, I.J., and Bennett, M.D. 2004. Genome downsizing in polyploid plants. Biol. J. Linn. Soc. 82(4): 651-663. doi:10.1111/j. 1095-8312.2004.00349.x.

Levy, A.A., and Feldman, M. 2002. The impact of polyploidy on grass genome evolution. Plant Physiol. 130(4): 1587-1593. doi:10.1104/pp.015727. PMID:12481041.

Liu, B., Vega, J.M., Segal, G., Abbo, S., Rodova, H., and Feldman, M. 1998. Rapid genomic changes in newly synthesized amphiploids of Triticum and Aegilops. I. Changes in low-copy noncoding DNA sequences. Genome, 41(2): 272-277. doi:10.1139/ gen-41-2-272.

Liu, B., Brubaker, C.L., Mergeai, G., Cronn, R.C., and Wendel, J.F. 2001. Polyploid formation in cotton is not accompanied by rapid genomic changes. Genome, 44(3): 321-330. doi:10.1139/ gen-44-3-321. PMID:11444689.

Ma, X.F., and Gustafson, J.P. 2005. Genome evolution of allopolyploids: a process of cytological and genetic diploidization. Cytogenet. Genome Res. 109(1-3): 236-249. doi:10.1159/ 000082406 . PMID: 15753583.

Ma, X.F., and Gustafson, J.P. 2006. Timing and rate of genome variation in triticale following allopolyploidization. Genome, 49(8): 950-958. doi:10.1139/G06-078. PMID:17036070.

Ma, X.F., and Gustafson, J.P. 2008. Allopolyploidization-accommodated genomic sequence changes in triticale. Ann. Bot. (Lond.), 101(6): 825-832. doi:10.1093/aob/mcm331.

Ma, X.F., Fang, P., and Gustafson, J.P. 2004. Polyploidizationinduced genome variation in triticale. Genome, 47(5): 839848. doi:10.1139/g04-051. PMID:15499398.

Madlung, A., Tyagi, A.P., Watson, B., Jiang, H.M., Kagochi, T., Doerge, R.W., et al. 2005. Genomic changes in synthetic Arabidopsis polyploids. Plant J. 41(2): 221-230. doi:10.1111/j.1365313X.2004.02297.x. PMID:15634199.

Milla, R., and Gustafson, J.P. 2001. Genetic and physical character- 
ization of chromosome 4DL in wheat. Genome, 44(5): 883-892. doi:10.1139/gen-44-5-883. PMID:11681613.

Neves, N., Silva, M., Heslop-Harrison, J.S., and Viegas, W. 1997. Nucleolar dominance in triticales: control by unlinked genes. Chromosome Res. 5(2): 125-131. doi:10.1023/ A:1018470208730. PMID:9146916.

Ozkan, H., Levy, A.A., and Feldman, M. 2001. Allopolyploidyinduced rapid genome evolution in the wheat (Aegilops-Triticum) group. Plant Cell, 13(8): 1735-1747. doi:10.1105/tpc.13. 8.1735. PMID: 11487689.

Ozkan, H., Tuna, M., and Arumuganathan, K. 2003. Nonadditive changes in genome size during allopolyploidization in the wheat (Aegilops-Triticum) group. J. Hered. 94(3): 260-264. doi:10. 1093/jhered/esg053. PMID:12816968.

Ramsay, L., Macaulay, M., Cardle, L., Morgante, M., degli Ivanissevich, S., Maestri, E., et al. 1999. Intimate association of microsatellite repeats with retrotransposons and other dispersed repetitive elements in barley. Plant J. 17(4): 415-425. doi:10. 1046/j.1365-313X.1999.00392.x. PMID:10205898.

Redi, C.A., Garagna, S., Zacharias, H., Zuccotti, M., and Capanna, E. 2001. The other chromatin. Chromosoma, 110(3): 136-147. doi:10.1007/s004120000114. PMID:11513289.

Röder, M.S., Korzun, V., Wendehake, K., Plaschke, J., Tixier, M.H., Leroy, P., and Ganal, M.W. 1998. A microsatellite map of wheat. Genetics, 149(4): 2007-2023. PMID:9691054.

Salmon, A., Ainouche, M.L., and Wendel, J.F. 2005. Genetic and epigenetic consequences of recent hybridization and polyploidy in Spartina (Poaceae). Mol. Ecol. 14(4): 1163-1175. doi:10. 1111/j.1365-294X.2005.02488.x. PMID:15773943.

Shaked, H., Kashkush, K., Ozkan, H., Feldman, M., and Levy, A.A. 2001. Sequence elimination and cytosine methylation are rapid and reproducible responses of the genome to wide hybridi- zation and allopolyploidy in wheat. Plant Cell, 13(8): 17491759. doi:10.1105/tpc.13.8.1749. PMID:11487690.

Song, K.M., Lu, P., Tang, K.L., and Osborn, T.C. 1995. Rapid genome change in synthetic polyploids of Brassica and its implications for polyploid evolution. Proc. Natl. Acad. Sci. U.S.A. 92(17): 7719-7723. doi:10.1073/pnas.92.17.7719. PMID: 7644483.

Tang, Z.X., Fu, S.L., Ren, Z.L., Zhou, J.P., Yan, B.J., and Zhang, H.Q. 2008. Variations of tandem repeat, regulatory element, and promoter regions revealed by wheat-rye amphiploids. Genome, 51(6): 399-408. doi:10.1139/G08-027. PMID:18521118.

Van't Hof, J., and Sparrow, A.H. 1963. A relationship between DNA content, nuclear volume, and minimum mitotic cycle time. Proc. Natl. Acad. Sci. U.S.A. 49(6): 897-902. doi:10. 1073/pnas.49.6.897. PMID:13996145.

Viegas, W., Neves, N., Silva, M., Caperta, A., and Morais-Cecílio, L. 2002. Nucleolar dominance: a "David and Goliath" chromatin imprinting process. Curr. Genomics, 3(6): 563-576. doi:10. 2174/1389202023350237.

Vitte, C., and Panaud, O. 2005. LTR retrotransposons and flowering plant genome size: emergence of the increase/decrease model. Cytogenet. Genome Res. 110(1-4): 91-107. doi:10. 1159/000084941. PMID:16093661.

Wendel, J.F. 2000. Genome evolution in polyploids. Plant Mol. Biol. 42(1): 225-249. doi:10.1023/A:1006392424384. PMID: 10688139.

Wolfe, K.H. 2001. Yesterday's polyploids and the mystery of diploidization. Nat. Rev. Genet. 2(5): 333-341. doi:10.1038/ 35072009. PMID:11331899.

Young, W.P., Schupp, J.M., and Keim, P. 1999. DNA methylation and AFLP marker distribution in the soybean genome. Theor. Appl. Genet. 99(5): 785-792. doi:10.1007/s001220051297. 